\title{
Hereditary thoracic aortic disease associated with cysteine substitution c.937T > G p. (Cys313Gly) in FBN1
}

\author{
E. Overwater · K. Van Rossum - M. J. H. Baars - A. Maugeri · A. C. Houweling
}

Published online: 12 June 2019

(c) The Author(s) 2019

A 56-year-old male was diagnosed with a type A aortic dissection, followed by a type $B$ dissection 3 years later. There were no other signs indicating a familial connective tissue disorder. Pathogenic variant c.937T $>$ G p.(Cys313Gly) in FBN1 [(NM_000138.4), Online Mendelian Inheritance in Man (OMIM) entry *134797] was identified by DNA testing, consistent with Marfan syndrome (OMIM entry \#154700). The variant was identified in 21 out of 53 tested relatives (Fig. 1). A thoracic aortic aneurysm was diagnosed in eight relatives carrying the variant, three of whom met the criteria for preventive surgery. One of the deceased obligate carriers probably had a thoracic aortic aneurysm. Most mutation carriers had a systemic score [1] of zero or one, although the highest score was four. As illustrated by this image, FBN1 variant c.937T $>$ G p.(Cys313Gly) can cause isolated aortic disease. Timely recognition of individuals with a pathogenic $F B N 1$ variant is highly important, as it enables the prevention of severe cardiovascular complications $[2,3]$.
Conflict of interest E. Overwater, K. Van Rossum, M.J.H. Baars, A. Maugeri and A.C. Houweling declare that they have no competing interests.

Ethical standards Written informed consent for publication was obtained from all the carriers of FBN1 variant c.937T > G p.(Cys313Gly).

Open Access This article is distributed under the terms of the Creative Commons Attribution 4.0 International License (http://creativecommons.org/licenses/by/4.0/), which permits unrestricted use, distribution, and reproduction in any medium, provided you give appropriate credit to the original author(s) and the source, provide a link to the Creative Commons license, and indicate if changes were made.

\section{References}

1. Loeys BL, Dietz HC, Braverman AC, Callewaert BL, De Backer J, Devereux RB, et al. The revised Ghent nosology for the Marfan syndrome. J Med Genet. 2010;47(7):476-85.

2. Regalado ES, Guo DC, Santos-Cortez RL, Hostetler E, Bensend TA, Pannu H, et al. Pathogenic FBN1 variants in familial thoracic aortic aneurysms and dissections. Clin Genet. 2016;89(6):719-23.

3. Rurali E, Perrucci GL, Pilato CA, Pini A, Gaetano R, Nigro P, etal. Precise therapy for thoracic aortic aneurysm in Marfan syndrome: a puzzle nearing its solution. Prog Cardiovasc Dis. 2018;61 (3-4:328-35.

\footnotetext{
E. Overwater $(\bowtie) \cdot$ M. J. H. Baars

Department of Clinical Genetics, Amsterdam UMC,

University of Amsterdam, Amsterdam, The Netherlands e.overwater@amc.nl

E. Overwater · K. Van Rossum · A. Maugeri · A. C. Houweling Department of Clinical Genetics, Amsterdam UMC, Vrije Universiteit Amsterdam, Amsterdam, The Netherlands
} 


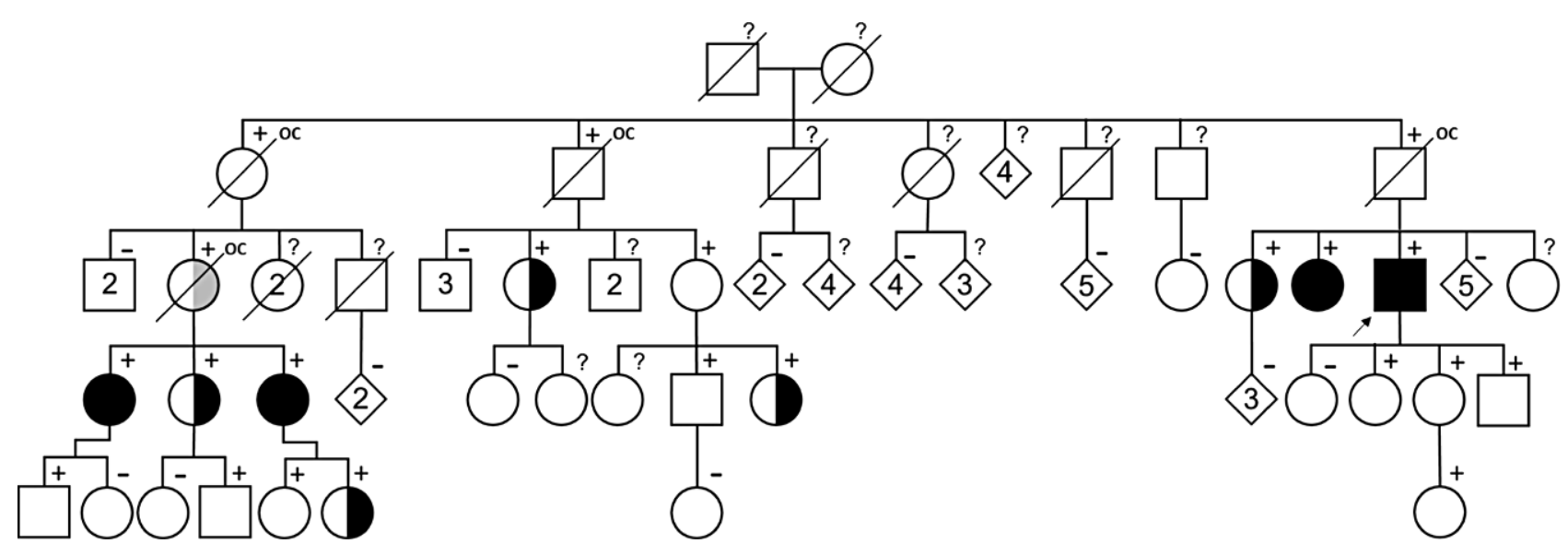

$+\quad$ Carrier of heterozygous variant c.937T > G
p.(Cys313Gly)

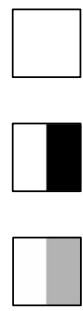

No cardiovascular involvement

- Wild type

Thoracic aortic aneurysm (confirmed)

Thoracic aortic aneurysm (anamnestic)

Proband

Thoracic aortic dissection or (preventive) surgery

Fig. 1 Pedigree depicting thoracic aortic aneurysms and/or dissections. Squares represent males, circles indicate females 